\title{
Darstellung von $\mathbf{V} \mathbf{a}$ und $\mathbf{V} \mathbf{b}$
}

$400 \mathrm{mg}$ Ia, 0,006 Mol Aldehyd, 0,06 ml Piperidin, 0,18 ml Eisessig in $50 \mathrm{ml}$ Benzol wurden $16 \mathrm{Stdn}$. am Wasserabscheider gekocht. Nach Abdampfen des Lösungsmittels wurde der Rückstand umkristallisiert, bzw. sublimiert (Tab. 2).

\section{Darstellung von VIa und VIb}

$100 \mathrm{mg}$ Va bzw. Vb wurden in Äther bei $-70^{\circ}$ mit einer äther. Lösung von $\mathrm{CH}_{2} \mathrm{~N}_{2}$ behandelt. Nach Abdampfen des Lösungsmittels wurde der Rückstand aus Benzol/P $P$. umkristallisiert.

\section{VIa: $\mathrm{C}_{20} \mathrm{H}_{28} \mathrm{~N}_{4} \mathrm{O}_{8}$. Ber. $\mathrm{N} 12,38$. Gef. $\mathrm{N} 12,90$.}

Die Verbindung VIb konnte nicht analysiert werden, da sie sich zu rasch zersetzte.

Für die Aufnahme der Spektren dienten die folgenden Geräte:

UV: Spectronic 505 der Fa. Bausch \& Lomb.

IR: Infracord 237 der Fa. Perkin-EImer.

NMR: A 60 A der Fa. Varian.

Massenspektren : MS 9 der Fa. AEI, Manchester (Tonisierungsenergie: $70 \mathrm{eV}$ ).

Herrn $H$. Bieler danken wir für die Durchfübrung der Mikroanalysen.

\section{Errata}

In der ersten Zeile des (engl.) Summaries zur Abhandlung von O. Hromatka, D. Binder und M.Knollmiller, Mh. Chem. 99, 1062 (1968), lese man: $\beta$-chloroethane- (nicht $\beta$-chloromethane-).

In der 5. Zeile von Tabelle 1 der Abhandlung von O. Beckmann. H. Boller und H. Nowotny, Mh. Chem. 99, S. 1581, lese man $(x \approx 0,6)$ [statt $(x \approx \gamma 6)]$.

Herausgeber: Akademie der Wissenschaften, Dr.-Ignaz-Seipel-Platz 2, A-1010 Wien, und Verein Österr. Chemiker, Wschenbachgasse 9, A-1010 Wien. - Verlag: Springer-Verlag, Mölkerbastei 5, A-1010 Wien. - Für den Textteil verantwortlich: Prof. Dr. F. Kuffner, Wăhringer Straße 38, A-1090 Wien. - Für den Anzeigenteil verantwortlich: Alois Hailwax, Paracelsusgasse 8 . A-1030 Wien. - Druck: Adolf Holzhausens Nachfolger, Kandlgasse 19-21, A-1070 Wien. 